\title{
Transient atrial fibrillation in hypertensive patients with thiazide induced hypokalaemia
}

\author{
M.K. Emara and A.M. Saadet \\ Department of Medicine, Mubarak Hospital, Kuwait.
}

\begin{abstract}
Summary: During the previous 34 months, 3 hypertensive patients on long-term thiazide therapy were admitted to the medical department, Mubarak Hospital, Kuwait, with atrial fibrillation (AF) and hypokalaemia. They received potassium chloride by intravenous infusion, followed by oral therapy with reversion to sinus rhythm. There were no clinical, electrocardiographic, radiological, or echocardiographic signs of cardiac or pericardial disease, and the other usual cases of AF were also excluded. The contribution of thiazide-induced hypokalaemia to the occurrence of AF in our patients is discussed.
\end{abstract}

\section{Introduction}

Most thiazide-induced hypokalaemia is mild and its significance in otherwise healthy hypertensives is unclear. A serum potassium between $2.5-3.4 \mathrm{mmol} / 1$ was sustained over a 2-year period in $23 \%$ of patients (VAC study, 1972). Increasing evidence, however, points to the risk of developing cardiac arrhythmias in some of these patients (MRC trial, 1983). An increased incidence of ventricular fibrillation was also reported in hypokalaemic patients after acute myocardial infarction (Nordrehauge \& Von der Lippe, 1983).

We report here 3 hypertensive patients on long-term thiazide therapy presenting with atrial fibrillation and hypokalaemia.

\section{Patients}

Clinical details are given in Table I. The three patients were on long-term chlorthalidone therapy, without potassium supplementation. A previous history of recurrent palpitations was obtained from the second patient only.

On admission, no signs of heart failure were present in any of the three patients, and the ventricular rate ranged between $120-140 /$ minute.

When the results of serum electrolytes were available, potassium chloride, in a dose of $20 \mathrm{mmol} 4$ hourly

Correspondence: M.K. Emara M.B., D.M., D.C.V.D., F.R.C.P. (Ed), F.R.C.P. Dept. of Medicine, Faculty of Medicine, Kuwait University, P.O. Box 24923, Safat - 13110, Kuwait.

Accepted: 24 June 1986 was given by intravenous infusion for the first 24 hours. This was replaced by $20 \mathrm{mmol}$ oral slow release potassium chloride 6 hourly with monitoring of serum electrolytes. AF reverted to sinus rhythm, 5-10 hours after starting intravenous potassium therapy. When serum potassium reached $4 \mathrm{mmol} / 1$, oral potassium was replaced by a potassium sparing diuretic. The dose of methyldopa was increased in patients (1) and (2), to obtain better control of blood pressure.

None of the three patients had any clinical, electrocardiographic, radiological or echocardiographic evidence of cardiac or pericardial disease. Thyroid function studies done in each case (including thyrotrophin releasing hormone stimulation test) yielded normal results.

Pulmonary embolism was excluded by the presence of normal arterial blood gases, and pulmonary perfusion scans. There were no clinical, electrocardiographic or laboratory signs suggestive of acute myocardial infarction in any of the cases. Other laboratory tests, including complete blood count, urine analysis, and biochemistry were normal apart from hypokalaemia and slight rise in bicarbonate. It was not possible to do a serum magnesium estimation.

During the follow-up period (11-34 months) serum electrolytes were within the normal range, and there was no history of palpitations suggestive of recurrence of atrial fibrillation.

Three months after discharge, a 24 hour Holter monitor was done for each patient. No significant abnormalities were detected in any of the records apart from occasional supraventricular and ventricular ectopic beats. 
Table I Clinical characteristics of the three patients

\begin{tabular}{|c|c|c|c|}
\hline & Case I & Case II & Case III \\
\hline Sex & Female & Male & Male \\
\hline Age (years) & 52 & 48 & 44 \\
\hline Antihypertensive & Methyldopa $0.25 \mathrm{~g} \times 3$ & & Methyldopa $0.25 \mathrm{~g} \times 2$ \\
\hline therapy (daily) & Chlorthalidone & Chlorthalidone & Chlorthalidone \\
\hline & $50 \mathrm{mg}$ & $100 \mathrm{mg}$ & $50 \mathrm{mg}$ \\
\hline $\begin{array}{l}\text { Approximate duration } \\
\text { of therapy (years) }\end{array}$ & 3 & 3 & 8 \\
\hline Clinical presentation & $\begin{array}{l}\text { Dizziness + } \\
\text { Palpitations }\end{array}$ & Palpitations & Palpitations \\
\hline $\begin{array}{l}\text { Blood pressure on } \\
\text { admission }(\mathrm{mmHg})\end{array}$ & $160 / 110$ & $170 / 100$ & $170 / 115$ \\
\hline $\begin{array}{l}\text { Serum potassium on } \\
\text { admission }(\mathrm{mmol} / \mathrm{l})\end{array}$ & 2.7 & 2.8 & 2.8 \\
\hline $\begin{array}{l}\text { Serum bicarbonate } \\
(\mathrm{mmol} / \mathrm{l})\end{array}$ & 28 & 28 & 27 \\
\hline $\begin{array}{l}\text { Duration of AF after } \\
\text { starting i.v. potassium } \\
\text { (hours) }\end{array}$ & 8 & 5 & 10 \\
\hline $\begin{array}{l}\text { Duration of follow-up } \\
\text { (months) }\end{array}$ & 34 & 14 & 11 \\
\hline
\end{tabular}

\section{Discussion}

Atrial fibrillation which may initially be paroxysmal, before becoming persistent, is a recognized complication of hypertension. In a group of hospitalized patients, hypertensive heart disease was present in $35 \%$ of cases with paroxysmal atrial fibrillation (Takahashi et al., 1981). Atrial fibrillation occurs mainly in the presence of hypertensive heart disease and cardiac failure is usually present (Freidberg, 1966). The Framingham study revealed that hypertension unaccompanied by signs of left ventricular enlargement or cardiac failure is very weakly correlated with atrial fibrillation (Kannel et al., 1982). There was no evidence of cardiac enlargement or cardiac failure in any of our patients. The relationship of atrial fibrillation to hypokalaemia is evidenced by the absence of any further clinically recognized episodes of atrial fibrillation during the follow-up period when serum potassium was maintained within the normal range. Most probably our patients had transient rather than paroxysmal atrial fibrillation and this makes 'lone' atrial fibrillation unlikely. Other causes of transient atrial fibrillation are pulmonary embolism, acute myocardial infarction, pericarditis, postoperative, and pneumonia (Sloan, 1982). There was no evidence of any of these in our patients.

Hypokalaemia is known to facilitate ectopic atrial and ventricular beats by either re-entry or automatic mechanisms (Schwartz, 1978). In the presence of ischaemic heart disease, mild hypokalaemia may lead to ventricular electrical instability and serious ventricular arrhythmias (Stewart et al., 1985). In the presence of an appropriate anatomical substrate in some patients, e.g. intra-atrial conduction defects $8 \mathrm{r}^{\circ}$ bypass, atrial fibrillation may also be induced (Mos, $\overrightarrow{0}$ 1984). Its occurrence is favoured by accelerated polarization of the atrial muscle, and such an electr physiological change may result from hypokalaemia@ (Olsson, 1971).

Measuring whole body potassium in hypertensive patients receiving prolonged thiazide therapy revealed that a fall of $1.0 \mathrm{mmol} / 1$ in plasma potassium is usually associated with a reduction of about $20 \%$ of the totalo body potassium (Edmonds \& Jasani, 1972). Our 3 patients were receiving a dose of chlorthalidone (a long acting diuretic), 4 times the ceiling antihypertensive dose (Silas, 1985). This might have contributed to the severity of potassium depletion.

The relationship between atrial muscle potassium 3 and post-operative atrial fibrillation in cardiaci patients was studied by taking pre-operative atrial biopsies (Ebert, 1970). Patients developing post- -0 operative atrial fibrillation had significantly lower potassium than patients remaining in sinus rhythm.

Hypokalaemia is also considered one of the main causes of atrial fibrillation in paediatric age groups $\widetilde{N}$ (Bellet, 1971).

Atrial fibrillation and atrial flutter are intimately related in terms of the fundamental mechanism in- $\omega$ volved in the genesis (Chung, 1983). It was possible in a hypertensive patient with atrial flutter, thiazideinduced hypokalaemia, and a clinically normal heart, $\stackrel{\infty}{\oplus}$ to re-induce the arrhythmia after its termination, by 
rapid atrial stimulation. This occurred only in the presence of hypokalaemia but not after its correction (Varriale et al., 1983). The occurrence of atrial fibrillation in hypertensive patients without clinical evidence of hypertensive heart disease may be due to other cardiac or extracardiac causes. We believe that in our cases, thiazide-induced hypokalaemia acted as a main

\section{References}

BELLET, S. (1971). In Clinical Disorders of the Heart Beat, 3rd edition. p. 720, Lea, Febiger: Philadelphia.

CHUNG, E. (1983). In Principles of Cardiac Arrhythmias, 3rd edition. p. 141. Williams \& Wilkins: Baltimore, London.

EDMONDS, C. \& JASANI, B. (1972). Total body potassium in hypertensive patients during prolonged diuretic therapy, Lancet, ii, 8.

EBERT, P. (1970). Relationship of myocardial potassium content and atrial fibrillation. Circulation, 11 (Suppl), 137.

FREIDBERG, C.K. (1966). In Diseases of the Heart, 3rd edition, p. 1487. W.B. Saunders: Philadelphia, London.

KANNEL, W., ABBOTT, R., SAVAGE, D. \& MCNAMARA, P. (1982). Epidemiologic features of chronic atrial fibrillation. New England Journal of Medicine, 306, 1018.

MOSS, A. (1984). Atrial fibrillation and cerebral embolism. Archives of Neurology, 41, 707.

MRC WORKING PARTY ON MILD TO MODERATE HYPERTENSION. (1983). Ventricular extra systoles during thiazide treatment. Sub-study of MRC mild hypertension trial. British Medical Journal, 287, 1249.

NORDREHAUGE, J.E. \& VON DER LIPPE, G. (1983). Hypokalaemia and ventricular fibrillation in acute myocardial infarction. British Heart Journal, 50, 525. factor in inducing atrial fibrillation, and suggests that this needs further study.

\section{Acknowledgement}

We would like to thank Mrs Aloma D'Souza for secretarial assistance.

OLSSON, S. (1981). Role of potassium in atrial fibrillation. Acta Medica Scandinavica, 647 (suppl), 33.

SCHWARTZ, A. (1978). Potassium-related cardiac arrhythmias and their treatment. Angiology, 29, 194.

SILAS, J.H. (1985). Drug treatment of hypertension. In Drugs in the Management of Heart Disease, Breckenridge, A. (ed). p. 131. MTP Press: Lancaster, Boston, The Hague, Dordrecht.

SLOAN, R. (1982). Atrial fibrillation. American Family Physician, 25, 165.

STEWART, D., IKRAM, H., ESPINEN, E. \& NICHOLLS, M. (1985). Arrhythmia potential of diuretic induced hypokalemia in patients with mild hypertension and ischaemic heart disease. British Heart Journal., 54, 290.

TAKAHASHI, N., SEKI, A., IMATAKA, K. \& FAJII, J. (1981). Clinical features of paroxysmal atrial fibrillation. Japanese Heart Journal, 22, 143.

VARRIALE, P., RAYMOND, K \& PARIKH, N. (1983). Atrial flutter secondary to hypokalaemia. Pace, 16, 8.

VAC STUDY (1972). Effects of treatment on morbidity in hypertension. Circulation, 45, 901.

WHELTON, P. (1984). Diuretics and arrhythmias in the Medical Research Council Trial. Drugs, 28 (Suppl), 54. 